\title{
A global perspective: what the data from the WHO project Atlas-ID tells us about the type of treatment used towards persons with intellectual disability throughout the world Jocelin Lecomte
}

\author{
Address: Montreal PAHO/WHO Collaborating Center for Reference and Research in Mental Health - West Montreal, Lisette-Dupras and Gabrielle- \\ Major readaptation centers, 8000 Notre-Dame, Montreal Quebec H8R 1H2, Canada \\ from WPA Thematic Conference. Coercive Treatment in Psychiatry: A Comprehensive Review \\ Dresden, Germany. 6-8 June 2007
}

Published: 19 December 2007

BMC Psychiatry 2007, 7(Suppl I):S39 doi:10.1 I86/I47I-244X-7-SI-S39

This abstract is available from: http://www.biomedcentral.com/I47I-244X/7/SI/S39

(c) 2007 Lecomte; licensee BioMed Central Ltd.

The WHO Atlas on Country Resources for Intellectual Disabilities (Atlas-ID) has been initiated under the umbrella of the "Atlas Project" begun in 2000 by the World Health Organization (WHO). The main purpose of the WHO Atlas Project, as a part of the mission of WHO, is to offer technical support to its member countries in the development of quality health services. Within this framework, the Atlas seeks to make available to WHO Member States useful information concerning available resources, within a specific context. The aim of this project is to gather, compile and disseminate data on resources and services offered within a given field throughout the world. WHO has already published six different volumes of Atlas. An Atlas relating specifically to resources and services offered in the field of intellectual disabilities was deemed necessary to present available data in the field and to acquire an overview of the country situations towards persons with ID. After consultation with experts in the field of ID, a questionnaire and an accompanying glossary were developed. This questionnaire covers a number of topics, pertaining to presence or lack of country resources in ID. It was sent to the national respondents of the 192 Member States of WHO. The questionnaire data was analyzed according to the region the countries belong to, their population size and income level. The data was also triangulated with the available information in the specialized literature. The data collection phase, completed in early 2007, has given an indication of the global situation on the level of development of availability of resources and services in each particular WHO region as well as the type of treatment used towards persons with intellectual disability throughout the world. The lack of reliable information, especially in low and middle income countries, justifies the usefulness of the Atlas-ID as a tool to support the development of research knowledge for advocacy and policy. 